\title{
Controllable synthesis of two-dimensional tungsten nitride nanosheets as electrocatalysts for oxygen reduction reaction
}

\author{
Jie Zhang, Jinwei Chen*, Yan Luo, Yihan Chen, Maryam Kiani, Xiaoyang Wei, Rui Luo, \\ Gang Wang and Ruilin Wang*
}

\begin{abstract}
A facile synthetic strategy was developed for insitu preparation of two-dimensional (2D) highly crystalline tungsten nitride (WN) nanosheets with controllable morphology as oxygen reduction reaction (ORR) catalysts. The dependence of the crystal structure and morphology of $\mathrm{WN}$ on $\mathrm{K}_{2} \mathrm{SO}_{4}$ content, $\mathrm{pH}$, and pyrolysis temperature was thoroughly examined. The electrocatalytic performance of $\mathrm{WN}$ toward ORR in an alkaline electrolyte indicated that $\mathrm{K}^{+}$plays an important role in the control of size and shape in the hydrothermal and nitridation process, thereby promoting the formation of plate-like $\mathrm{WO}_{3}$ and $2 \mathrm{D} \mathrm{WN}$ nanosheets. The WN nanosheets, with largely exposed edge sites, provide abundant catalytic active sites and allow fast charge transfer. Furthermore, they exhibit high stability for ORR and methanol tolerance.
\end{abstract}

Keywords: tungsten nitride, nanosheets, electrocatalysts, oxygen reduction reaction

\section{INTRODUCTION}

Direct methanol fuel cells (DMFCs) have been widely explored because of their high energy density, high efficiency, and quick start-up time at a low operating temperature [1-3]. Oxygen reduction reaction (ORR) catalysts for the cathodic reaction of DMFCs have been extensively investigated to replace platinum-containing groups, with the aim of enhancing the catalytic activity of ORR while reducing the cost $[4,5]$. A number of alternative ORR catalysts including non-precious metal (NPM), metal composites, and metal-free composites have been recently considered as potential substitutes for platinum-containing groups catalysts. As a consequence of recent advances in the field of NPM catalysts, several transition metal-based electrocatalysts, such as transition metal carbides [6,7], transition metal dichalcogenides $[8,9]$, transition metal phosphides [10], transition metal oxides [11-13], and transition metal nitrides (TMNs) [14-16], have been developed for the purpose of illuminating the catalytic mechanism and achieving excellent electrocatalytic performance.

Among these catalysts, TMNs have been comprehensively examined because of their potential applications in fuel cells, which result from their high electrical and thermal conductivity, excellent electronic properties, and chemical resistance to corrosion in aqueous media. However, their large-scale production and practical applications have been hindered by difficulties associated with facet control that arises from inferior anisotropy and rigorous high-temperature synthesis routes during nitridation [17]. In an attempt to solve these problems, nitride nanostructures with uniform dispersion, specific facet exposure, and unique architectures have been prepared, including tungsten nitride nanocrystals [18], single crystalline-like molybdenum nitride nanobelts [19], VN hollow spheres [20], layered $\mathrm{Co}_{3} \mathrm{Mo}_{2} \mathrm{O}_{x} \mathrm{~N}_{6-x}$ [21], and alloyed Co-Mo nitride [22]. In many cases, nitrides not only serve as support for loading noble metals with synergistic effects but also act as ORR catalysts.

Two-dimensional (2D) nanostructures find application in the fabrication of high-performance supercapacitors, lithium-ion batteries, and biosensors because they can provide large specific surface area, short transport distance, and good conducting pathways in electrochemical reactions [23-26]. However, to date, few studies have been conducted on 2D TMN crystals for ORR in fuel cells. These structures present a nanoscale dimension in 
the $c$-axis and growth from an exposed edge and show the potential for ORR catalysts because their unique electronic structure and morphology allow the modulation of electron transport and the enhancement of $2 \mathrm{D}$ host capabilities [27,28]. Among 2D structures of the active materials, highly dispersed nitrides nanosheets not only possess a high nitrogen content, and large aspect ratios but also exhibit an excellent electrical conductivity. For example, a new form of hybrid $\mathrm{NiC}-\mathrm{Ni}_{3} \mathrm{~N}$ nanosheets was served as a robust catalyst for the hydrogen evolution reaction because it is chemically stable and metallically conductive [29]. Therefore, we believe that 2D TMN applications in fuel cells should be further investigated and developed.

In this study, 2D tungsten nitride nanosheets (denoted as WN NSs) were designed and fabricated through simple hydrothermal synthesis followed by nitridation. Hydrothermal synthesis was performed to obtain $\mathrm{WO}_{3}$ nanostructures, which were subsequently subjected to calcination in an $\mathrm{NH}_{3}$ atmosphere to ensure that an oxygen atom in $\mathrm{WO}_{3}$ was completely substituted by a nitrogen atom. This method proved to be low cost, template- and organic solvent-free, and environmentfriendly. The underlying relationship between crystal structure characteristics and preparation conditions was also elucidated. Both ORR performance and stability were analyzed by linear sweep voltammetry (LSV) and chronopotentiometry.

\section{EXPERIMENTAL SECTION}

All reagents were of analytical purity and used as received. A schematic of the $2 \mathrm{D}$ WN NS synthesis is shown in Fig. 1. For the synthesis of $\mathrm{WO}_{3}$ with different morphologies, $3.5 \mathrm{mmol} \mathrm{Na}_{2} \mathrm{WO}_{4} \cdot 2 \mathrm{H}_{2} \mathrm{O}$ and $1.75 \mathrm{mmol}$ $\mathrm{K}_{2} \mathrm{SO}_{4}$ were dissolved in $40 \mathrm{~mL}$ of deionized (DI) water with magnetic stirring to prepare a transparent solution. Then, $3 \mathrm{~mol} \mathrm{~L}{ }^{-1} \mathrm{HCl}$ solution was added into the suspension to adjust the $\mathrm{pH}$ value until the formation of yellow precipitates was observed. The mixture was transferred to a $100 \mathrm{~mL}$ Teflon-lined autoclave and held at $180^{\circ} \mathrm{C}$ for $12 \mathrm{~h}$. The yellow precipitates were then collected from the solution by filtration, washed with DI water and ethanol several times, and dried in a vacuum oven at $80^{\circ} \mathrm{C}$ overnight to obtain $\mathrm{WO}_{3}-\mathrm{K} 11(\mathrm{~W} / \mathrm{K}=1: 1)$.

For comparison, $\mathrm{WO}_{3}$ nanostructures with $\mathrm{W} / \mathrm{K}$ molar ratios of 4:1, 2:1, and 1:2, denoted as $\mathrm{WO}_{3}-\mathrm{K} 41, \mathrm{WO}_{3}-$ $\mathrm{K} 21$, and $\mathrm{WO}_{3}-\mathrm{K} 12$, respectively, were also prepared under the same conditions. The $\mathrm{WO}_{3}$ sample without $\mathrm{K}_{2} \mathrm{SO}_{4}$ was marked as $\mathrm{WO}_{3}-\mathrm{K} 0$. Finally, the resulting $\mathrm{WO}_{3}$ samples were annealed at $700^{\circ} \mathrm{C}$ for $3 \mathrm{~h}$ under an

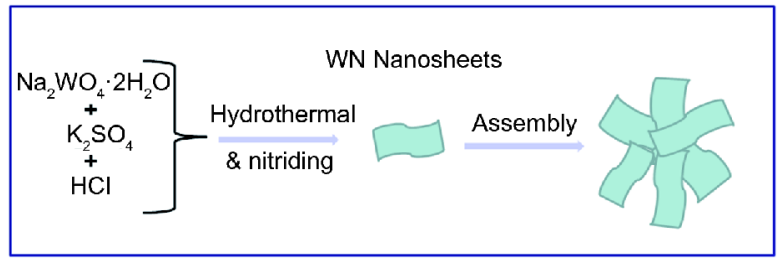

Figure 1 Schematic illustration of the preparation process of WN NSs.

$\mathrm{NH}_{3} / \mathrm{Ar}$ flow of $100 \mathrm{sccm}$ to produce the WN nanostructures.

X-ray diffraction (XRD) patterns were obtained using a powder diffractometer (DX-2700, Dandong, China) with a $\mathrm{Cu} \mathrm{Ka}$ radiation source. X-ray photoelectron spectroscopy (XPS) was carried out on a Kratos AxisULTRA Xray photoelectron spectrometer equipped with a $165 \mathrm{~mm}$ hemispherical electron energy analyzer. The morphological characteristics of the electrocatalysts were determined using a scanning electron microscope (SEM, JSM-5900LV, JEOL Co.) and a transmission electron microscope (TEM, Carl Zeiss SMT, Libra 200FE).

Rotating disk electrode (RDE) measurements were performed using a glassy carbon (GC) electrode with a typical three-electrode system. A graphite plate and $\mathrm{Ag} /$ $\mathrm{AgCl}$ electrode were used as the counter and reference electrodes, respectively. For the preparation of the working electrodes, $5 \mathrm{mg}$ of catalyst was ultrasonically suspended in a mixture of $1 \mathrm{~mL}$ of ethanol and $50 \mu \mathrm{L}$ of Nafion solution ( $5 \mathrm{wt} \%$, Du Pont) for $30 \mathrm{~min}$ to obtain a homogeneous ink. Then, $20 \mu \mathrm{L}$ of the catalyst ink was dropped onto a GC electrode with a diameter of $5 \mathrm{~mm}$ and dried under an infrared lamp. RDE measurements were performed on a Pine electrochemical system at rotating rates varying from $400 \mathrm{rpm}$ to $2,025 \mathrm{rpm}$ (revolutions per minute) with a scan rate of $10 \mathrm{mV} \mathrm{s}^{-1}$. The number of transferred electrons $(n)$ can be calculated according to the Koutecky-Levich (K-L) equation [30]: $J^{-1}=J_{\mathrm{k}}^{-1}+J_{\mathrm{L}}^{-1}=J_{\mathrm{k}}^{-1}+B^{-1} \omega^{0.5}$ and $B=0.2 n F D\left(\mathrm{O}_{2}\right)^{2 / 3} v^{-1 / 6} C\left(\mathrm{O}_{2}\right)$.

\section{RESULTS AND DISCUSSION}

Fig. 2a shows the XRD pattern of the $\mathrm{WO}_{3}$ samples prepared with different W/K molar ratios. For $\mathrm{WO}_{3}-\mathrm{K} 0$ and $\mathrm{WO}_{3}-\mathrm{K} 12$, the characteristic diffraction peaks corresponding to the monoclinic system of $\mathrm{WO}_{3}$ (JCPDS card no. $43-1035)$ are found at $23.2^{\circ}, 24.4^{\circ}, 26.5^{\circ}, 34.1^{\circ}$, $41.9^{\circ}, 49.8^{\circ}$, and $55.8^{\circ}$, respectively ascribed to the (002), (200), (120), (202), (222), (041), and (142) diffraction planes. In contrast, only the sharp peak of (002) can be detected in the patterns of $\mathrm{WO}_{3}-\mathrm{K} 41, \mathrm{WO}_{3}-\mathrm{K} 21$, and $\mathrm{WO}_{3}-\mathrm{K} 11$ with different $\mathrm{K}_{2} \mathrm{SO}_{4}$ contents, with relatively 

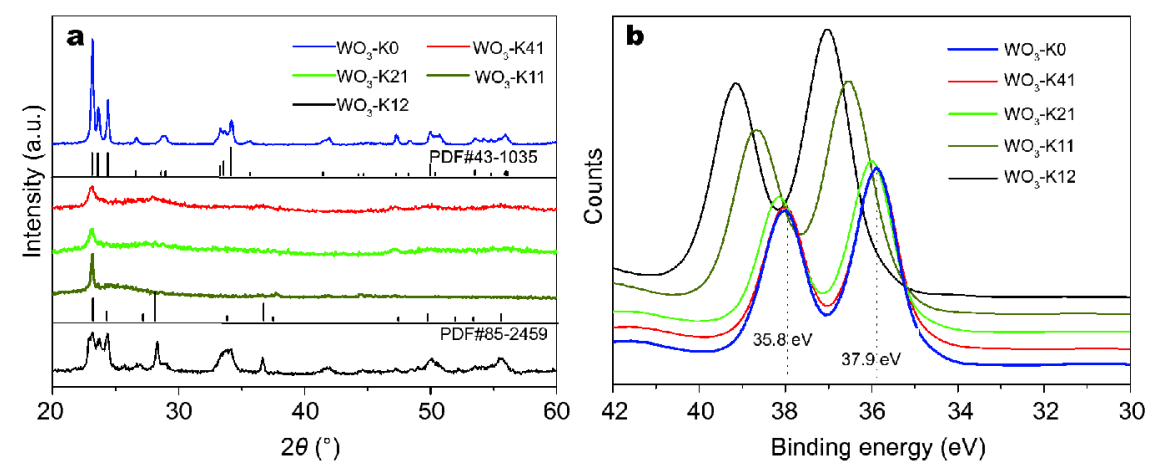

Figure 2 (a) XRD patterns of $\mathrm{WO}_{3}$ and (b) XPS spectra of W $4 \mathrm{f}$ in $\mathrm{WO}_{3}$ synthesized with the different W/K molar ratios.

weak intensity. These patterns match well with those of the hexagonal $\mathrm{WO}_{3}$ samples (JCPDS card No. 85-2459). This difference implies that the addition of $\mathrm{K}_{2} \mathrm{SO}_{4}$ causes $\mathrm{WO}_{3}$ to orient along the (002) direction. In $\mathrm{WO}_{3}-\mathrm{K} 0$ product (Fig. S1a), the $\mathrm{WO}_{3}$ nanostructures without the assistance of $\mathrm{K}_{2} \mathrm{SO}_{4}$ are mainly agglomerated. Fig. S1b displays that $\mathrm{WO}_{3}$ hydrothermally synthesized in the presence of a moderate amount of $\mathrm{K}_{2} \mathrm{SO}_{4}$ exhibits an assembly of nanoplates with a regular arrangement. $\mathrm{K}_{2} \mathrm{SO}_{4}$, which acts as an inductive agent, strongly influences the final morphology of $\mathrm{WO}_{3}$. Consistent with previous findings, our results indicate that the hexagonal $\mathrm{WO}_{3}$ phase is composed of layers stacked to form open onedimensional tunnels [31]. Fig. 2b illustrates the XPS spectra in the $\mathrm{W}$ and $\mathrm{K}$ regions of $\mathrm{WO}_{3}$. The binding energies (BEs) of $\mathrm{WO}_{3}-\mathrm{KO}$ at 35.8 and $37.9 \mathrm{eV}$ can be assigned to $\mathrm{W} 4 \mathrm{f}_{7 / 2}$ and $\mathrm{W} 4 \mathrm{f}_{5 / 2}$, respectively, which are similar to the reported values of 35.6 and $37.7 \mathrm{eV}$ [32]. However, the $\mathrm{BE}$ of $\mathrm{W}$ on $\mathrm{WO}_{3}$ is positively shifted to a high $\mathrm{BE}$ as the amount of $\mathrm{K}^{+}$significantly increases, thereby demonstrating that electron transfer occurs on the $\mathrm{WO}_{3}$ surface during the hydrothermal process. On the basis of the XPS results, it seems reasonable to conclude that $\mathrm{K}^{+}$is incorporated into the $\mathrm{WO}_{3}$ lattice.

For nitridation products, the SEM image (Fig. 3a) of $\mathrm{WN}-\mathrm{K} 0$ (obtained from $\mathrm{WO}_{3}-\mathrm{K} 0$ ) displays a severely agglomerated powder. As can be extracted from Fig. 3b$\mathrm{d}, \mathrm{WN}-\mathrm{K} 41, \mathrm{WN}-\mathrm{K} 21$, and $\mathrm{WN}-\mathrm{K} 11$ are well homogeneously distributed, exhibiting uniformly dispersed microstructures. On the other hand, for the sample with the highest amount of potassium salt (WN-K12; Fig. 3e), the bulk morphology is observed. These results indicate that the $\mathrm{K}^{+}$ions influences not only the formation of $\mathrm{WO}_{3}$ nanostructures but also the preferential growth of $\mathrm{WN}$ NSs along a certain lattice plane. WN-K11 exhibits the smallest nanostructure size among the specimens in-

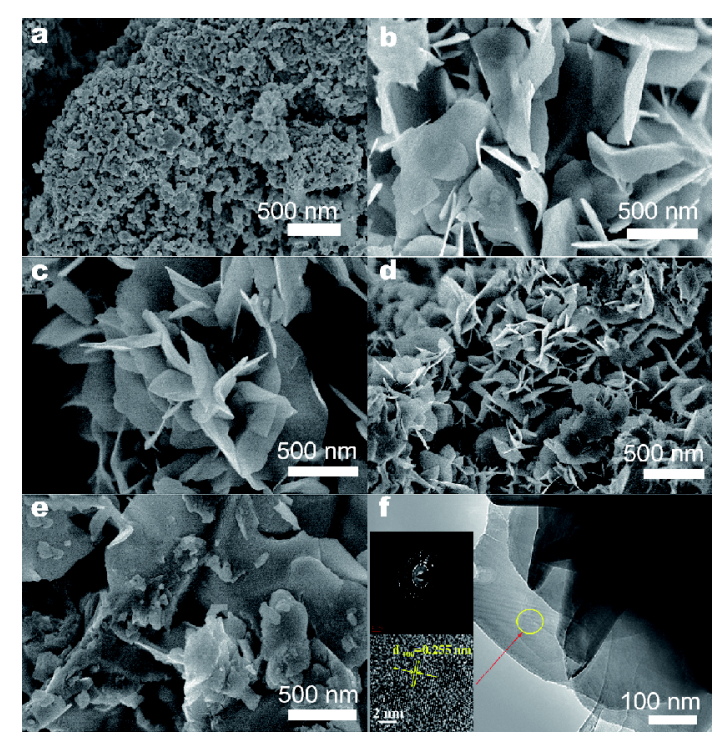

Figure 3 SEM images of (a) WN-K0, (b) WN-K41, (c) WN-K21, (d) WN-K11, (e) WN-K12, and (f) TEM image and SAED pattern (inset) of the WN-K11.

vestigated and high dispersion; consequently, a larger active surface area may be available in $\mathrm{WN}-\mathrm{K} 11$ for the electrochemistry reaction. In addition, the TEM image of an individual WN-K11 sample is shown in Fig. 3f.

The electron diffraction pattern of a selected area (inset) indicates a polycrystalline structure and a well-defined crystalline lattice with a lattice spacing of $0.255 \mathrm{~nm}$ corresponding to the (100) plane of hexagonal WN. The phase identity of WN-K11 (Fig. 4) was further confirmed by the XRD pattern corresponding to (100), (101), (110), and (200), which is also consistent with the hexagonal WN (JCPDS card No. 25-1256).

A formation mechanism of $\mathrm{WO}_{3}$ is illustrated in Fig. 5. Accordingly, in the initial reaction stage (I), colloidal $\mathrm{H}_{2} \mathrm{WO}_{4}$ is rapidly formed after the dropwise addition of 


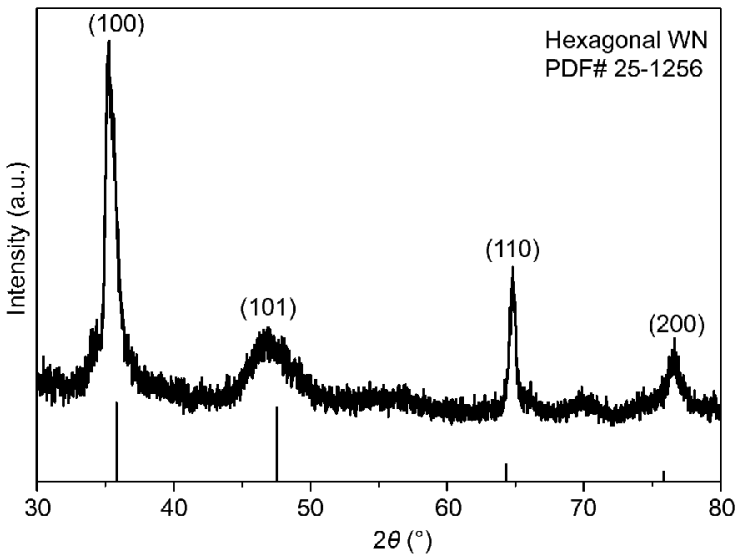

Figure 4 XRD pattern of WN-K11.

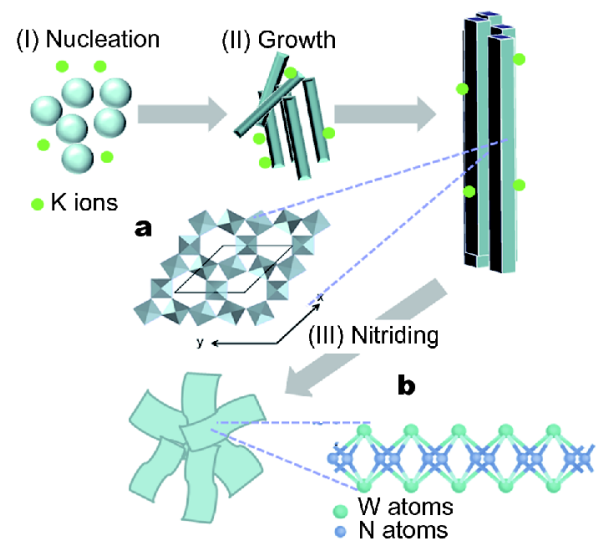

Figure 5 Formation process of the $\mathrm{WO}_{3}$ nanoplate and WN NSs. Inset (a) Schematic of the hexagonal $\mathrm{WO}_{3}$ viewed to the (002) crystal plane and (b) side-view of the WN NSs.

$\mathrm{HCl}$ into the solution containing $\mathrm{Na}_{2} \mathrm{WO}_{4}$ and $\mathrm{K}_{2} \mathrm{SO}_{4}$. Nucleation occurs, and a $\mathrm{WO}_{3}$ crystal is obtained at the beginning of the hydrothermal reaction [33]. In the second stage (II), the formation of hexagonal $\mathrm{WO}_{3}$ (Fig. 5a) can be attributed to the presence of $\mathrm{K}^{+}$ions, which stabilize the hexagonal structure by their adsorption onto the hexagonal channels preventing the thermodynamic conversion of $\mathrm{WO}_{3}$ into a monoclinic phase $[34,35]$. In the third stage involving nitridation (III) at $700^{\circ} \mathrm{C}$ for $3 \mathrm{~h}$, the hexagonal phase of the as-prepared $\mathrm{WN}$ maintains while a lattice contraction occurs. Fig. $5 \mathrm{~b}$ shows that the surfaces of WN contain apical W atoms, which hold the nitrogen atoms in the center of the structure and connect them to the basal plane of the hexagonal lattice. This finding confirms that $\mathrm{K}^{+}$also stabilizes the hexagonal structure of $\mathrm{WN}$, thereby constituting an ideal regulatory component for the formation of hexagonal WN NSs.
To gain more insight into the formation of the WN nanostructure, the nitridation experiment with the 1 : $1 \mathrm{~W} / \mathrm{K}$ molar ratio was conducted at different $\mathrm{pH}$ values. The SEM images of the as-grown samples are shown in Fig. S2. A mixture of nanosheets and smaller particles is obtained at pH 0.5 (Fig. S2a), whereas no such particles can be detected in the samples prepared at $\mathrm{pH} 1,1.5$, and 2. Moreover, the thickness of the sheets was found to increase from $\mathrm{pH} 1$ (Fig. 3d) to $\mathrm{pH} 2$ (Fig. S2c), possibly because the formation of $\mathrm{H}_{2} \mathrm{WO}_{4}$ is a fast reaction and numerous $\mathrm{H}^{+}$quickly react with $\mathrm{WO}_{4}{ }^{2-}$. High $\mathrm{H}^{+}$concentrations may inhibit the growth of grains on $\mathrm{WO}_{3}$, leading to the generation of $\mathrm{WN}$ particles at low $\mathrm{pH}$.

To investigate the effect of nitridation temperature on the formation of the $\mathrm{WN}$ nanostructure, we calcinated $\mathrm{WO}_{3}$ at 600 and $800^{\circ} \mathrm{C}$ (the as-prepared $\mathrm{WN}$ nanostructures were denoted as $\mathrm{WN}-600$ and $\mathrm{WN}-800$, respectively) while maintaining the other experimental parameters constant. The corresponding XRD results (Fig. S3) confirm the phase purity and crystal structure of WN. For WN-700 and WN-800, all the diffraction peaks can be well indexed to a hexagonal $\mathrm{WN}$ crystalline phase (JCPDS card no. 25-1256). Furthermore, the strong and sharp diffraction peaks from WN-700 indicate its good crystallinity and strong preferential growth direction along the (100) plane. Conversely, WN-600 presents the typical (111), (200), (311), and (222) diffraction peaks consistent with cubic WN (JCPDS card No. 65-2898). As can be seen in Fig. S4, WN-600 consists of abundant nanoparticles as a result of inadequate nitridation caused by low temperature. The SEM image of WN-700 and $\mathrm{WN}-800$ shows similar dispersible nanosheets, indicating that nitridation at 700 and $800^{\circ} \mathrm{C}$ transforms the nanoplates into $2 \mathrm{D}$ WN NSs, which is in accordance with the XRD result. We also evaluated the effect of nitridation time on the morphological characteristics of $\mathrm{WN}$, conducting the nitridation process at $700^{\circ} \mathrm{C}$ for 1 and $4 \mathrm{~h}$. Fig. S5 illustrates that no obvious changes are observed in the structure of WN obtained after $1 \mathrm{~h}$ calcination (denoted as $\mathrm{WN}-1 \mathrm{~h}$ ) compared with that of $\mathrm{WO}_{3}$, most likely because the short calcination time affords an insufficient nitridation reaction, with concomitant slight particle aggregation in the dominant layered product. When the process is extended for 3 or $4 \mathrm{~h}$, WN with a high purity and a smooth surface is formed. The XRD pattern in Fig. S6 shows that all the diffraction peaks for the as-prepared samples can be indexed to the WN phase. However, the intensity of the (100) peak corresponding to the $\mathrm{WN}$ structure prepared after $3 \mathrm{~h}$ nitridation is larger than that for the other samples, suggesting that nanocrystal growth 

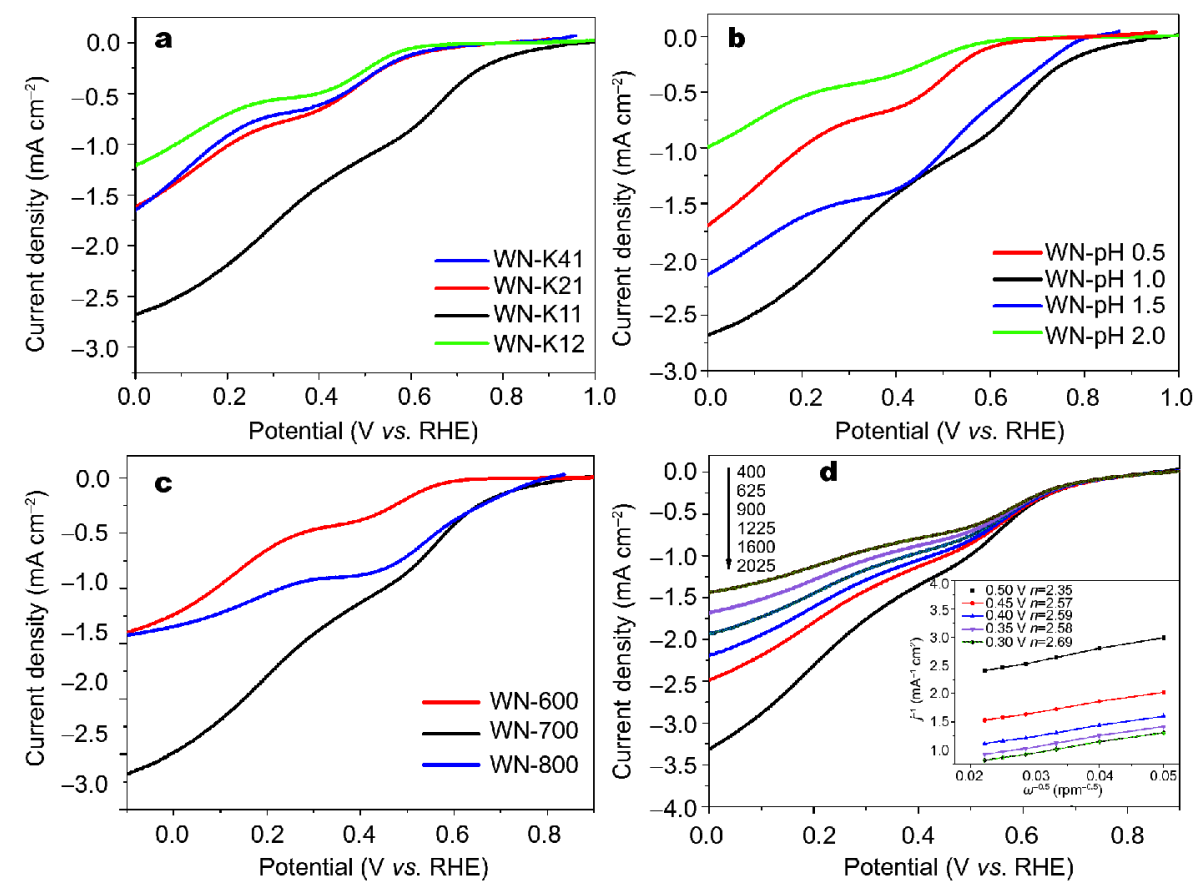

Figure 6 Linear sweeping voltammetry of (a) the WN prepared with different $\mathrm{W} / \mathrm{K}$ molar ratio, (b) WN prepared with various pH value during hydrothermal process, (c) WN prepared by different nitridation temperature, and (d) the WN with optimized synthetic condition at different rotation rates. The inset shows corresponding Koutecky-Levich plots at $0.30,0.35,0.40,0.45$ and $0.50 \mathrm{~V}$ ( $v s$. RHE), respectively, in $0.1 \mathrm{~mol} \mathrm{~L}^{-1} \mathrm{KOH}$ saturated with $\mathrm{O}_{2}$, scan rate: $10 \mathrm{mV} \mathrm{s}^{-1}$, rotating rate: $1,600 \mathrm{rpm}$.

occurs preferentially along the (100) plane with a high degree of crystallinity. Therefore, $3 \mathrm{~h}$ can be considered as the optimum nitridation time for the formation of $\mathrm{WN}$ NSs.

We tackled the evaluation of their activity and kinetic properties for ORR catalysis by performing RDE measurements. Fig. 6a shows that WN-K11 exhibits a more positive onset potential $\left(E_{\text {onset }}\right)$ and a higher current density than the WN samples prepared with other $\mathrm{W} / \mathrm{K}$ ratios. Consistent with the SEM results, the positive potential shift and the improved performance of $\mathrm{WN}-\mathrm{K} 11$ can be attributed to the enhancement of electron transfer from the 2D-layered structure to the adsorbed oxygen. Fig. $6 \mathrm{~b}$ illustrates the LSV curves of WN obtained at different $\mathrm{pH}$ values during the hydrothermal process. Among the catalysts, that obtained at $\mathrm{pH} 1$ (WN-pH1) exhibits the highest ORR activity, onset potential, and current density. As shown in Fig. 6c, the catalyst performance reaches a maximum when the nitridation temperature is $700^{\circ} \mathrm{C}$, and a minimum at $600^{\circ} \mathrm{C}$, indicating that $700^{\circ} \mathrm{C}$ is the optimum temperature for the formation of the exposed active sites. With the appropriate temperature, a desirable structure with rich active catalytic sites on the surface has been confirmed to facilitate electron transport during the catalytic process
[36]. The possible reason can be explained by XPS results, as shown in Fig. S7. The peaks at 32.7 and $34.8 \mathrm{eV}$ represent the BEs of $\mathrm{W} 4 \mathrm{f}$ in a pure WN NSs, which is consistent with a previous report [18]. Specially, the extended $\mathrm{N} 1 \mathrm{~s}$ peak of $\mathrm{WN}-700$ also suggests that numerous $\mathrm{N}$ atoms participate in the nitridation that affords electroconductivity of the nitride products. Therefore, optimal WN NSs are obtained with a $\mathrm{W} / \mathrm{K}$ ratio of 1 , at $\mathrm{pH} 1$, and on performing the nitridation at $700^{\circ} \mathrm{C}$ for $3 \mathrm{~h}$. Table S1 demonstrates the comparisons of $E_{\text {onset }}$ and half-wave potential $\left(E_{1 / 2}\right)$ among the various non-precious catalysts, where our prepared WN NSs displays an enhancement on $E_{\text {onset }}$ than that in some other reports.

From the slopes of the K-L plots at various potentials, the electron transfer number $(n)$ of WN NSs was determined to be 2.56 (Fig. 6d), indicating that ORR catalysis predominantly follows a two-electron transfer pathway. However, ORR catalyzed by $2 \mathrm{D}$ WN NSs is most likely a mixed process of two- and four-electron transfers because the $2 \mathrm{D}$ morphology provides fast electron transport pathways and a large electroactive surface, which diminishes the gap between the as-prepared $\mathrm{WN}$ and commercial Pt/C. Fig. S8a shows a ring current $\left(I_{\text {Ring }}\right)$ as compared to the disk current $\left(I_{\text {Disk }}\right)$ and the $n$ value calculated using the RRDE measurement data [37]: 

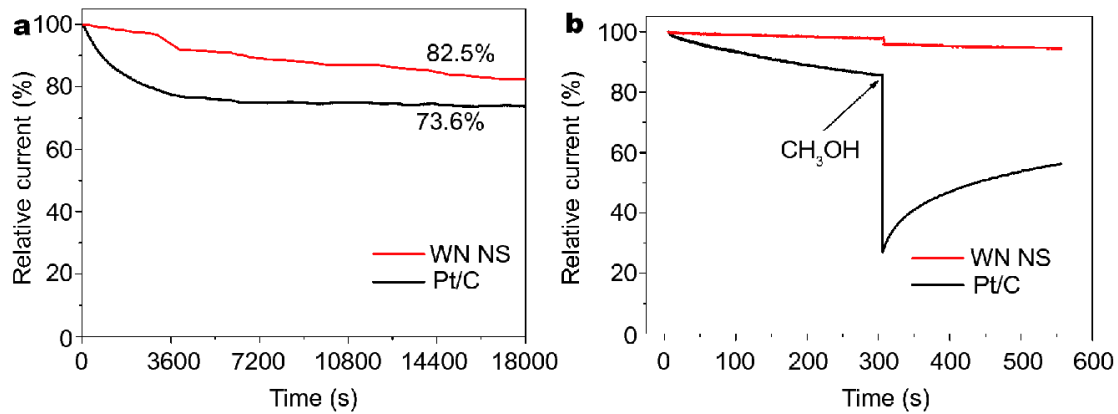

Figure 7 (a) Current-time chronoamperometric response of $\mathrm{Pt} / \mathrm{C}$ and WN NSs at $-0.35 \mathrm{~V}$ ( vs. $\mathrm{Ag} / \mathrm{AgCl}$ ) in $\mathrm{O}_{2}$-saturated $0.1 \mathrm{~mol} \mathrm{~L} \mathrm{LOH}^{-1} \mathrm{Kolution}$. (b) Chronoamperometric response of $\mathrm{Pt} / \mathrm{C}$ and WN NSs at $-0.35 \mathrm{~V}$ ( $v s . \mathrm{Ag} / \mathrm{AgCl}$ ) in $\mathrm{O}_{2}$-saturated $0.1 \mathrm{~mol} \mathrm{~L}^{-1} \mathrm{KOH}$ solution. The arrow indicates the introduction of $3 \mathrm{~mol} \mathrm{~L}^{-1}$ methanol.

$\% \mathrm{H}_{2} \mathrm{O}_{2}=\left(2 I_{\mathrm{R}} / N\right) /\left(I_{\mathrm{D}}+I_{\mathrm{R}} / N\right)$ and $n=4 I_{\mathrm{D}} /\left(I_{\mathrm{D}}+I_{\mathrm{R}} / N\right)$. The current collection efficiency $(N)$ of the Pt ring is determined to be 0.37 using standard redox couple of ferri/ferrocyanide. Furthermore, the amount of $\mathrm{H}_{2} \mathrm{O}_{2}$ produced by the above process also was confirmed by RRDE measurements (Fig. S8b). The $n$ value is in good agreement with those obtained from the K-L plots that are based on the RDE measurements, confirming that ORR kinetics for the WN NSs sample is mainly through a mixed process of two- and four-electron transfer. The maximal $\mathrm{H}_{2} \mathrm{O}_{2}$ yield of WN NSs is $12.6 \%$, which is similar to that of previous reports in the potential range of $0.3-0.5 \mathrm{~V}$ [38].

To evaluate the durability of WN NSs as ORR catalysts, we conducted chronoamperometric measurements in $0.1 \mathrm{~mol} \mathrm{~L}^{-1} \mathrm{O}_{2}$-saturated $\mathrm{KOH}$ solution for $18,000 \mathrm{~s}$ at $-0.35 \mathrm{~V}$ (vs. Ag/AgCl). Fig. 7a shows that the WN catalyst exhibits good electrochemical durability, with current losses of $17.5 \%$ after $18,000 \mathrm{~s}$. To provide comparison, Pt/ $\mathrm{C}$ was tested under the same conditions, affording obvious activity decay with $27 \%$ retention. Because methanol tolerance is another crucial parameter for ORR electrocatalysts [39], the chronoamperometric responses of the WN electrode on the addition of $3 \mathrm{~mol} \mathrm{~L}^{-1}$ methanol were evaluated in comparison with those of commercial Pt/C (Fig. 7b). The current density of the Pt/ $\mathrm{C}$ electrode was found to decrease sharply after the addition of $3 \mathrm{~mol} \mathrm{~L}^{-1}$ methanol to the $0.1 \mathrm{~mol} \mathrm{~L}^{-1} \mathrm{O}_{2}$-saturated $\mathrm{KOH}$ solution, whereas the current density of the WN electrode remained virtually unaltered. These findings demonstrate that the tolerance of $\mathrm{WN}$ electrodes against methanol is stronger than that of commercial Pt/ C electrodes.

\section{CONCLUSIONS}

WN NSs were synthesized by self-assembly construction based on a hydrothermal strategy combined with ni- tridation. $\mathrm{K}_{2} \mathrm{SO}_{4}$ acts as an inductive agent for the formation of lamellar nanoplates in the hydrothermal synthesis, and favors the crystallization of $2 \mathrm{D}$ WN NSs during the high-temperature nitridation. The morphology of $\mathrm{WO}_{3}$ and $\mathrm{WN}$ can be controlled by adjusting the preparation conditions, such as $\mathrm{pH}$, nitridation temperature, nitridation time, $\mathrm{K}^{+}$content, and catalytic activity. Optimal WN NSs can be synthesized at $\mathrm{W} / \mathrm{K}$ ratio $=1, \mathrm{pH} \mathrm{1}$, and nitridation conditions of $700^{\circ} \mathrm{C}$ and $3 \mathrm{~h}$ reaction. The $2 \mathrm{D}$ morphology of WN NSs leads to a desirable ORR performance. Taken together, these findings strongly suggest that WN NSs are promising Pt-free cathodic electrocatalysts for ORR in alkaline fuel cells.

Received 27 January 2018; accepted 27 March 2018;

published online 17 April 2018

1 Kothandaraman R, Nallathambi V, Artyushkova K, et al. Nonprecious oxygen reduction catalysts prepared by high-pressure pyrolysis for low-temperature fuel cells. Appl Catal B-Environ, 2009, 92: 209-216

2 Sheng W, Bivens AP, Myint MNZ, et al. Non-precious metal electrocatalysts with high activity for hydrogen oxidation reaction in alkaline electrolytes. Energy Environ Sci, 2014, 7: 1719-1724

3 Stephens IEL, Bondarenko AS, Grønbjerg U, et al. Understanding the electrocatalysis of oxygen reduction on platinum and its alloys. Energy Environ Sci, 2012, 5: 6744-6762

4 Wang G, Xu T, Wen S, et al. Structure-dependent electrocatalytic activity of $\mathrm{La}_{1-x} \mathrm{Sr}_{x} \mathrm{MnO}_{3}$ for oxygen reduction reaction. Sci China Chem, 2015, 58: 871-878

5 Wang T, Wang J, Wang X, et al. Graphene-templated synthesis of sandwich-like porous carbon nanosheets for efficient oxygen reduction reaction in both alkaline and acidic media. Sci China Mater, 2018, doi: 10.1007/s40843-017-9191-5

6 Yang J, Xie Y, Wang R, et al. Synergistic effect of tungsten carbide and palladium on graphene for promoted ethanol electrooxidation. ACS Appl Mater Interfaces, 2013, 5: 6571-6579

7 Ko AR, Lee YW, Moon JS, et al. Ordered mesoporous tungsten carbide nanoplates as non-Pt catalysts for oxygen reduction reaction. Appl Catal A-General, 2014, 477: 102-108

8 Tan SM, Chua CK, Sedmidubský D, et al. Electrochemistry of 
layered GaSe and GeS: applications to ORR, OER and HER. Phys Chem Chem Phys, 2016, 18: 1699-1711

9 Du C, Huang H, Feng X, et al. Confining $\mathrm{MoS}_{2}$ nanodots in 3D porous nitrogen-doped graphene with amendable ORR performance. J Mater Chem A, 2015, 3: 7616-7622

10 Zhang G, Wang G, Liu Y, et al. Highly active and stable catalysts of phytic acid-derivative transition metal phosphides for full water splitting. J Am Chem Soc, 2016, 138: 14686-14693

11 Osgood H, Devaguptapu SV, Xu H, et al. Transition metal (Fe, Co, $\mathrm{Ni}$, and $\mathrm{Mn}$ ) oxides for oxygen reduction and evolution bifunctional catalysts in alkaline media. Nano Today, 2016, 11: 601-625

12 Zhang G, Xu Y, Wang L, et al. Rational design of graphene oxide and its hollow $\mathrm{CoO}$ composite for superior oxygen reduction reaction. Sci China Mater, 2015, 58: 534-542

13 Sun M, Liu H, Liu Y, et al. Graphene-based transition metal oxide nanocomposites for the oxygen reduction reaction. Nanoscale, 2015, 7: 1250-1269

14 Yan $\mathrm{H}$, Meng M, Wang L, et al. Small-sized tungsten nitride anchoring into a 3D CNT-rGO framework as a superior bifunctional catalyst for the methanol oxidation and oxygen reduction reactions. Nano Res, 2015, 9: 329-343

15 Huang K, Bi K, Liang C, et al. Novel VN/C nanocomposites as methanol-tolerant oxygen reduction electrocatalyst in alkaline electrolyte. Sci Rep, 2015, 5: 11351

16 Huang T, Mao S, Zhou G, et al. Hydrothermal synthesis of vanadium nitride and modulation of its catalytic performance for oxygen reduction reaction. Nanoscale, 2014, 6: 9608-9613

17 Xie J, Xie Y. Transition metal nitrides for electrocatalytic energy conversion: opportunities and challenges. Chem Eur J, 2016, 22: 3588-3598

18 Dong Y, Li J. Tungsten nitride nanocrystals on nitrogen-doped carbon black as efficient electrocatalysts for oxygen reduction reactions. Chem Commun, 2015, 51: 572-575

19 Liu J, Huang K, Tang HL, et al. Porous and single-crystalline-like molybdenum nitride nanobelts as a non-noble electrocatalyst for alkaline fuel cells and electrode materials for supercapacitors. Int $J$ Hydrogen Energy, 2016, 41: 996-1001

20 Zhao D, Cui Z, Wang S, et al. VN hollow spheres assembled from porous nanosheets for high-performance lithium storage and the oxygen reduction reaction. J Mater Chem A, 2016, 4: 7914-7923

21 An L, Xia Z, Chen $\mathrm{P}$, et al. Layered transition metal oxynitride $\mathrm{Co}_{3} \mathrm{Mo}_{2} \mathrm{O}_{x} \mathrm{~N}_{6-x} / \mathrm{C}$ catalyst for oxygen reduction reaction. ACS Appl Mater Interfaces, 2016, 8: 29536-29542

22 Sun $\mathrm{T}, \mathrm{Wu} \mathrm{Q}$, Che R, et al. Alloyed Co-Mo nitride as high-performance electrocatalyst for oxygen reduction in acidic medium. ACS Catal, 2016, 5: 1857-1862

23 Bissett MA, Worrall SD, Kinloch IA, et al. Comparison of twodimensional transition metal dichalcogenides for electrochemical supercapacitors. Electrochim Acta, 2016, 201: 30-37

24 Park HC, Kim SJ, Kim MC, et al. Tungsten nitride nanoplates as an anode material for lithium ion batteries. Ceramics Int, 2016, 42: 1933-1942

25 Xiong M, Rong Q, Meng HM, et al. Two-dimensional graphitic carbon nitride nanosheets for biosensing applications. Biosens Bioelectron, 2016, 89: 212-223

26 Zhang G, Liu H, Qu J, et al. Two-dimensional layered $\mathrm{MoS}_{2}$ : rational design, properties and electrochemical applications. Energy Environ Sci, 2016, 9: 1190-1209
27 Zhang S, Wang Q, Kawazoe Y, et al. Three-dimensional metallic boron nitride. J Am Chem Soc, 2013, 135: 18216-18221

28 Seo JW, Jun YW, Park SW, et al. Two-dimensional nanosheet crystals. Angew Chem Int Ed, 2007, 46: 8828-8831

29 Yin J, Fan Q, Li Y, et al. Ni-C-N nanosheets as catalyst for hydrogen evolution reaction. J Am Chem Soc, 2016, 138: 1454614549

30 Li R, Shao X, Li S, et al. Metal-free N-doped carbon nanofibers as an efficient catalyst for oxygen reduction reactions in alkaline and acid media. Nanotechnology, 2016, 27: 505402

31 Lian C, Xiao X, Chen Z, et al. Preparation of hexagonal ultrathin $\mathrm{WO}_{3}$ nano-ribbons and their electrochemical performance as an anode material in lithium ion batteries. Nano Res, 2016, 9: 435-441

32 Yan $\mathrm{H}$, Tian C, Sun L, et al. Small-sized and high-dispersed WN from $\left[\mathrm{SiO}_{4}\left(\mathrm{~W}_{3} \mathrm{O}_{9}\right)_{4}\right]^{4-}$ clusters loading on GO-derived graphene as promising carriers for methanol electro-oxidation. Energy Environ Sci, 2014, 7: 1939-1949

33 Miao B, Zeng W, Hussain S, et al. Large scale hydrothermal synthesis of monodisperse hexagonal $\mathrm{WO}_{3}$ nanowire and the growth mechanism. Mater Lett, 2015, 147: 12-15

34 Her YC, Chang CC. Facile synthesis of one-dimensional crystalline/amorphous tungsten oxide core/shell heterostructures with balanced electrochromic properties. CrystEngComm, 2014, 16: 5379-5386

35 Szilagyi IM, Madarasz J, Pokol G, et al. Stability and controlled composition of hexagonal $\mathrm{WO}_{3}$. Chem Mater, 2008, 20: 4116-4125

36 Li Y, Wang Y, Pattengale B, et al. High-index faceted $\mathrm{CuFeS}_{2}$ nanosheets with enhanced behavior for boosting hydrogen evolution reaction. Nanoscale, 2017, 9: 9230-9237

37 Li XR, Li XL, Xu MC, et al. Gold nanodendrities on graphene oxide nanosheets for oxygen reduction reaction. J Mater Chem A, 2014, 2: 1697-1703

38 Liu B, Huang B, Lin C, et al. Porous carbon supported Fe-N-C composite as an efficient electrocatalyst for oxygen reduction reaction in alkaline and acidic media. Appl Surf Sci, 2017, 411: 487493

39 Zhang G, Jin X, Li H, et al. N-doped crumpled graphene: bottomup synthesis and its superior oxygen reduction performance. Sci China Mater, 2016, 59: 337-347

Acknowledgements This work was supported by the National Natural Science Foundation of China (21306119), the Key Research and Development Projects in Sichuan Province (2017GZ0397, 2017CC0017), and the Science and Technology Project of Chengdu (2015-HM0100531-SF).

Author contributions Zhang J and Chen JW designed the experiments. Zhang J, Luo Y, Chen YH, Kiani M and Wei XY helped with the sample characterization. Luo R and Wang G participated in the interpretation of experimental results. Zhang J wrote the paper with support from Chen JW and Wang RL. All authors contributed to the general discussion.

Conflict of interest The authors declare that they have no conflict of interest.

Supplementary information Supporting data are available in the online version of the paper. 


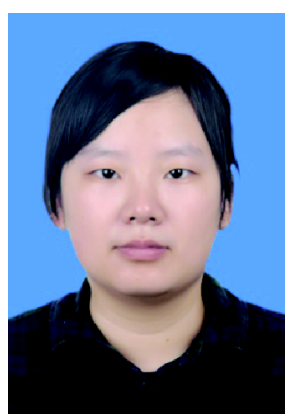

Jie Zhang received her PhD degree in materials physics and chemistry from Sichuan University in 2017. She is currently a postdoctoral research fellow for energy materials and devices in the College of Materials Science and Engineering of Sichuan University under the supervision of Prof. Ruilin Wang. Her main research interest is focused on the non-precious metal electrocatalysts of the fuel cells.

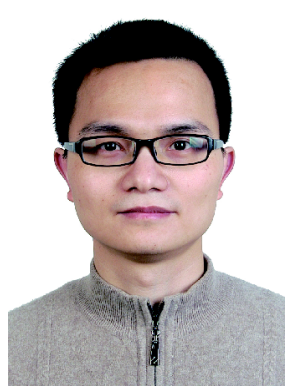

Jinwei Chen is currently an associate professor in the College of Materials Science and Engineering at Sichuan University. $\mathrm{He}$ received his $\mathrm{PhD}$ degree from College of Materials Science and Engineering at Sichuan University in 2010. His research interests are in the areas of nanostructured functional materials and their application in sustainable energy and clean environment technologies.

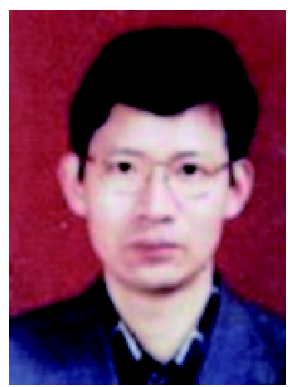

Ruilin Wang is a full professor in the College of Materials Science and Engineering at Sichuan University. He received his PhD degree from Department of Chemistry at Bath University in 1999. He worked in Oxford University, Bath University and Imperial College London as a postdoctoral research associate for 4 years. His research interests are in the areas of photoelectrochemistry and electrochemistry related fields.

\section{二维氮化铇纳米片催化剂的可控制备及其氧还原性能研究}

张洁, 陈金伟 ${ }^{*}$, 罗艳, 陈奕含, Maryam Kiani, 魏小洋, 罗瑞, 王刚, 王瑞林 ${ }^{*}$

摘要 本文以铇酸钠和硫酸钾等试剂为原料, 采用水热结合氨气氮化的方法原位获得了一种二维的氮化铇 (WN) 晶体, 并将其作为氧还原 (ORR) 反应的催化剂. 通过控制和优化制备条件(水热过程中硫酸钾含量、 $\mathrm{pH}$ 值以及氮化条件包括氮化温度和氮化时间), 实现了纳米WN 的可控制备. 